\title{
Technology Initiatives Derailed in U.S Early Education Schools: Should Leadership Redesign the Organizational Blueprint?
}

\author{
Michelle Lee Manganaro \\ University of Phoenix \\ USA
}

\begin{abstract}
Where and when innovation occurs in the United States (U.S.) early education schools depends greatly on the congruency of long-standing workplace norms, access to resources, and the actual oversight of school leadership. Norms include many factors not the least of which is a work groups' desire to improve. Resource access is controlled in large part by the government, both local and national. And finally, oversight of work methods and organizational communications is difficult for early education school leadership due to the high educator turnover rate, educator qualifications and traits, such as the emotionalintelligence of the work group, and the low rate of pay for the industry. Although government initiatives and individual school initiatives alike frequently focus on 'quality service', the workforce is simultaneously challenged with emotional intelligence factors. Leadership education of school leaders must collaborate a wide set of divergent perceptions of what constitutes quality service and which organizational communication will be enhanced by technology. The examination of data in a November 2012 survey focuses on what the educators perceive, what technology educators have access to, how educators are using technologies they have access to, and what educators view as connected among technologies and school quality.
\end{abstract}

Key words: early childhood, preschool, technology, leadership

\section{Introduction}

Where and when innovation occurs in the United States (U.S.) early

\footnotetext{
Correspondence concerning this report should be addressed to Michelle Lee Manganaro, Faculty, Massasoit Community College, Brockton, MA and faculty, University of Phoenix, Phoenix, AZ, USA at PO BOX 291, Duxbury, MA 02331, USA. Electronic mail may be sent to michellemanganaro@gmail.com
}

education schools depends greatly on the congruence of long-standing workplace norms, access to resources, and the actual oversight of school leadership. Norms include many factors not the least of which is a work group's desire to improve. Resource access is controlled in large part by the government, both local and national. And finally, oversight of work methods and organizational communications is difficult for early education school 
leadership due to the high educator turnover rate, educator qualifications and traits, such as the emotional intelligence (the ability to perceive, control and evaluate emotions) of the work group, and the low rate of pay for the industry.

The workforce of early education teachers in the United States is generally female, under-educated, and over-worked (U. S. Census, 2013a) when considering the time spent physically teaching and supervising children when compared to time spent properly planning programs for children, their families, and the employee workplace. Although government initiatives and individual school initiatives alike are frequently focused on "quality service", the workforce is simultaneously challenged with emotional intelligence in attempting to collaborate with a wide set of divergent perceptions of what constitutes quality service. Further, the involvement of collaborative efforts with colleagues continues to be a compromising and even derailing aspect of organizational growth (Shonkoff \& Phillips, 2000; Winnicott, 2002).

Particularly challenging to the early childhood service industry is the longterm cultural and industry-wide collective adversity to change initiatives in general and a clear dichotomy in human attitude and value or lack thereof placed on the progress that technology represents (Sheridan \& Schuster, 2001; Shlay, Tran, Weinraug, \& Harmon, 2005). These mounting perceptual challenges present blockages at the government level and the individual school site level and preclude most work groups from benefitting from the full potential involving technology initiatives; preventing some states and individual schools from even pursuing the idea (U. S. Department of Education, 2000).

\section{Background}

Theoretically, innovation is necessary for quality improvement in the cycle of organizational life (Nishiguchi, 2001; Scott, 2003; Steensman \& Corley, 2001). Yet, with regard to innovative thinking or announcements of new initiatives, the typical U. S. early educator lacks education or experience needed to view multiple sides of an issue. Definition of the typical U. S. early educator includes terms such as 'preschool teacher', 'day care worker', 'early childhood professional', and 'educator'. The credential for entrylevel educator is typically less than one year in the classroom and one, fortyhour college course (U.S. Census Bureau, 2012a). In this project, the term educator will be used to denote all employees caring for children under the age of 5 years. Entry level educators and long-term educators have different views on the usefulness or uselessness of technology and the impact of this divergence is powerful. Age, personality, and length of time in the industry each play a factor in the perception of change. Although information and communication are categorically valued 
by educators in the early education industry, change is seen as a negative occurrence with entry-level and veteran educators who are comfortable with the way things are going. Whether the adversity has to do with cultural factors and backgrounds of the professionals in this service industry is unknown. This project seeks to explore the variables concerning educator thinking to infer what connects to and affects future Information and Communication Technology (ICT) planning in early education schools.

Local and national political and legislative initiatives involving Information and Communication Technology (ICT) are embraced by some school leaders; however, because there are constant (at least annual) regulatory changes, even inspired innovators (leaders and educators alike) become exhausted with updating the policies and procedures. This supports the basic research question behind this project: How are new workplace ideas and governmentrelated initiatives involving the way information and communication perceived by educators? If negatively perceived, why? If positively, received, what are the outcomes?

In general, Information and Communication Technology (ICT) enable leadership and management to control work flows and monitor work (Green, 2004). Service-oriented and manufacturing-oriented industries alike require training and innovative efforts for knowledge workers. Training is also required for product and system assessment and improvements. Knowing the use and impact of technology depends greatly on understanding the organizational context from which one views the technologies and related successes.

Steensma and Corley (2001) indicate technology sourcing has boundaries that are contingent on leadership risk taking potential. From this viewpoint, organizational leadership can propose and implement generative technologies (Zittrain, 2005) that lead to organizational change, improvement, or innovation. In early education schools, the organizational cultures that are resistant to change may impede such generative technologies and resulting innovation. In such a case, not only are the effectiveness of the school and the school's programs at risk, but also the primary clients of the organization, the small children under 6 years of age and their families. Leadership at each school site and the government have historically worked at varying rates and speeds in order to lead improvement initiatives (Shonkoff \& Phillips, 2000).

\section{Hypotheses}

In the United States, within the Commonwealth of Massachusetts, the Department of Education (DOE) has embarked on several new projects involving technologies for individual school sites over the past five years. They were previously managed from separate DOE technology departments 
and Internet sites but there now exists one entry point to a web-based system for school leaders to enter and monitor the following data: teacher qualifications, criminal records investigation, and school quality rating criteria.

In 2010 and 2011, Massachusetts early education school leaders were notified by the Department of Early Education and Care (EEC), the agency that regulates individual school sites, that the online systems were now required. These Information and Communication Technology (ICT) initiatives also involved a number of charges to individual educators who should $\log$ in and create profiles as well as $\log$ in and self-report the specifics of annual professional trainings. In Hypotheses 1, 2, and 3, this project focuses on how these technologies challenge the workforce, leaders and educators.

\section{Hypothesis 1}

Early education school educators have a negative perception of the Information and Communication Technology (ICT) initiatives regulated by the Massachusetts Department of Education (DOE).

\section{Hypothesis 2}

Early education school educators perceive that time taken to complete the Information and Communication Technology (ICT) initiatives regulated by the Massachusetts, the Department of Education (DOE) is time that is taken away from their regular work duties.

\section{Hypothesis 3}

Early education school educators give feedback involving the Information and Communication Technology (ICT) initiatives regulated by the Massachusetts Department of Education (DOE) to the effect that time spent on these systems derails other quality initiatives.

There are also a set of State- and Nationally-approved curriculum and child assessment technologies which are linked to funding or accreditation approval that involve a series of applications, including some on-line systems, where educators can enter lesson plans, classroom observations, and assess individual child skills. Familiarity, training, and time for these technologies demand a shift from the previous work habits of many educators who would handwrite child assessment informally, individually create lesson plans with great academic freedom, and teach a curriculum that emerged from the class interests. In hypothesis 4, this project explores what technologies the schools are independently using in their daily operations to monitor and assess quality.

\section{Hypothesis 4}

Early education school educators give favorable feedback involving the Information and Communication Technology (ICT) initiatives suggested by state regulations and national accreditations and in their feedback, educators point to areas that individual school leadership can focus on to guide effective innovation efforts. 


\section{Methodology}

The exploratory, mixed methods study began during November 2012, with an investigation through an online survey making inquiry to 518 schools in the Commonwealth of Massachusetts. This was done using a 2012 email list of active educators and administrators that was made public, using email addresses which are updated routinely on State Resource and Referral Agency mailings.

\section{Subjects}

Reply emails to the survey solicitation arrived from 422 prospective participants, indicating a willingness of 422 individuals, who were either educators, administrators, or other practitioners in the early education field. Subsequently two participants indicated they could not participate based on employment contract obligations.

\section{Survey Instruments and Process}

The first survey, conducted in November 2012, was designed to look into the training areas and internal developments involving how information and communication are shared among stakeholders such as educators and parents, within each of the schools. Variables coming from the blind surveys provided data that would help design the questions for part two of the mixed methods study (Creswell, 2009). There were ten participants that skipped the survey questions in the first survey. The option requiring a response was incorporated into the second survey, which probed further into related data areas and was sent to the same participants. A stated incentive for participating was that participants would receive a copy of the aggregate results and any final publishing concerning the study.

The November 2012 survey inquired about areas concerning Information and Communication Technology (ICT) initiatives that were recently made mandatory by state regulations and other process management technologies suggested by national accreditation in recent years. Other feedback from the participating educators was also obtained in some questions with an option to respond with comments. Exposed factors reported by the participating early educators identified several areas of satisfaction and dissatisfaction concerning information and communication and other types of organizational technologies the participants viewed as pertinent to quality school outcomes. The research questions meant to be answered by the results in the November 2012 survey are:

RQ1: What training do the participants have?

RQ2: What experience or knowledge do the participants have concerning Information and Communication Technology (ICT) initiatives that were recently made mandatory by state regulations and other process management technologies suggested by national accreditation 
in recent years?

RQ3: What communication or organizational technologies do the participants view as pertinent to quality school outcomes?

The examination of data in the November 2012 survey, focused on what the educators perceive, what technology educators have access to, how educators are using technologies they have access to, and what educators view as connected among technologies and school quality. Perceptions and quality factors were coded and deciphered based on what the survey participants commonly reported in the two-part survey.

A January 2013 survey was developed with consideration of participant responses from the prior survey and questions examined variables involving the types of longstanding workplace norms, types of access to resources, and the types of actual oversight of school leadership. Analyses between the two surveys provided inferential connections linking quality factors reported by the school educators to areas of focus from the school leaders. The preliminary questions involved in the second survey are:

RQ4: What workplace beliefs or norms did the participants experience?

RQ5: What types of ICT access to resources did participants have?

RQ6: What type of oversight did participants' superiors have?
Quantitative results included commentary for the qualitative elements, which involved factor analysis of latent factors. The analyses and results of this exploratory, mixed methods study leave practitioners with a set of new ideas for creating a blueprint toward technology integration at the local and individual school levels. The analyses also leave regulators and accreditation agencies with some areas for consideration.

\section{Data Analyses: Findings, and Variables}

\section{November 2012 Survey: Educator Training}

Concerning training areas, all participants reported having some college or more training specific to early childhood and a majority split among having a 4-year degree and having some college plus other training (Table 1). Typical involvement in degree programs has been on the rise in Massachusetts over the past ten years due to the various Department of Early Education and Care (EEC) approval to fund Education and Provider Support (EPS) grants (EEC, 2013).

Beyond the pursuit of a college degree, specific areas of training reported included curriculum, health and safety, Montessori training, cognitive, executive function, social/ emotional. There were no significant replies that occurred as a majority. The array of replies included 60 different topics. However, use of text analyses revealed that areas relevant to either 
Table 1. Participant Highest Level of Education in Early Childhood

Help us know who is completing this survey: What is your highest level of formal education *with an early childhood focus*?

\begin{tabular}{c|c|c}
\hline Answer options & Response percent & Response count \\
\hline Less than high School & $0.0 \%$ & 0 \\
\hline Some workshops & $0.0 \%$ & 0 \\
\hline Some college courses & $3.2 \%$ & 10 \\
\hline Some college courses plus additional hours & $35.5 \%$ & 110 \\
\hline Associates degree in early childhood education & $16.1 \%$ & 50 \\
\hline Bachelor's degree in early childhood education & $32.3 \%$ & 100 \\
\hline Master's degree in early childhood education & $12.9 \%$ & 40 \\
\hline Doctorate degree in early childhood education & $0.0 \%$ & 0 \\
\hline
\end{tabular}

program planning or behavior were categorically present in the majority of replies. Interesting to the current project was the fact that there were no noted training areas reported that included the words 'communication' or 'technology' nor any mention of the state mandated systems for reporting educator training.

\section{Technology in the Workplace for Early Educators}

Within each school site, educators were asked to report their comfort level with internal technology developments at their site of employment in the question that asked, "Does your place of employment, where you conduct educator-related duties, have computers and Internet accessible to you that you use routinely to fulfill your job description?" Here 58.8 percent $(n=182)$ of responding participants (310) reported having computers with Internet accessible to them in order to fulfill their duties (Table 2). Comments offered as part of this query indicated a lack of time to use the resources and at times, a lack of clarity in the way they were supposed to use the computer. Non-conclusive but still noteworthy were two stand-alone comments:

"Online learning is vital for busy educators! I am looking forward to a fellowship experience this spring, but have not previously participated in one. I believe it will be a unique experience! Additionally, my organization has a leadership focus series that has been invaluable for leadership development and encouraging staff to reach for higher goals" (anonymous, unnamed survey participant)." 
Table 2. Participants with Access to a Computer and Internet in the Workplace

Does your place of employment, where you conduct educator-related duties, have computers and Internet accessible to you that you use routinely to fulfill your job description?

\begin{tabular}{|c|c|c|}
\hline Answer options & Response percent & Response count \\
\hline Yes & $58.5 \%$ & 240 \\
\hline No & $41.5 \%$ & 170 \\
\hline & Answered question & 410 \\
\hline & Skipped question & 10 \\
\hline
\end{tabular}

"The use of the computer and internet has done little to enhance my education and knowledge of preschoolers" (anonymous, unnamed survey participant)."

In four questions involving the participants' school sites, the November 2012 survey inquired about Information and Communication Technology (ICT), specifically, "Did technology enable leadership and management to monitor work" as inspired by Green (2004). A large majority of 97 percent $(n=397)$ of responding participants reported that website, email, and social media were used by their school leadership. In response to a question asking did the participant obtain training concerning the Massachusetts initiatives to create an online profile with EEC and selfreport their training hours, a small majority of 72.5 percent $(\mathrm{n}=297)$ reported having received training from their organization and comments reflected self-training at home.

Concerning training required for child assessment and program improvements, a minority of 34 percent
( $n=139)$ of the participants reported receiving on-site training. Many commented about specific assessment tools and online surveys their organizations used. Analyses of latent variables revealed no statistical significance in the comments offered. In the last related query, which was inspired by the idea of generative technologies (Zittrain, 2005), the question inquired if the participant thought that information and communication moved by technology promoted positive changes, improvement, or innovation at their site. Here, a majority of 82 percent $(n=337)$ of participants reported a "yes", 14\% $(\mathrm{n}=57)$ indicated "I don't know", and 4 percent $(n=16)$ indicated "no" they did not see technology as a vehicle for change, improvement, or innovation.

\section{State Required and Other Online Reporting Technologies}

In the November 2012 survey questions concerning participant views on technologies that promoted communications between the educator and outside agencies, two different outcomes were reported. First, with 
regard to the EEC's Professional Registry Profile requirement and selfreporting, participants largely reported a favorable response to the related questions. Closed questions such as "Are you familiar with the EEC Professional Registry, Profile, and requirement to self-report your professional training?" yielded a 94 percent $(n=385)$ response or better. Participants reported a high degree of comfort with using the information and communication technology and also a high degree of trust with this particular technology. In questions associated with the use of online child assessments or social media, however, the participants were not as comfortable, familiar, or trusting as depicted in comments in participant survey responses. Analyses of latent variables lead to variables concerning the perception of online child-assessment tools and/or social media tools as "unsafe", "impersonal", and causing "time-management" issues for educators.

In early education schools, organizational culture has a direct impact on the attitudes of the staff group and the resulting quality of the environment (Bruno, 2009; Gonzalez-Mena \& Eyre, 2004; Nonaka, Konno, \& Toyama, 2001; Sheridan \& Schussster, 2001). As a result, accepted norms within a school environment, may lead educators to either accept or reject generative technologies and resulting innovation. To inquire more about the attitudes and belief systems within these workplaces, the second survey was composed to delve in to related areas.

\section{The January 2013 Survey: New Research Questions}

The design of the January 2013 survey was originally set up to seek variables involving the types of longstanding workplace norms, types of ICT access to resources, and the types of actual oversight of school leadership. Variables from the November 2012 survey documented three new areas for inquiry, which were included in the January 2013 survey. As a result, three additional research questions stemming from the data and variables were formulated:

RQ7: Could online resources help with program planning or behavior management?

RQ8: How did online training help educators with access to information?

RQ9: To what degree did participants have an adversity to change?

\section{Workplace Beliefs and Norms}

Based on an extensive literature review spanning the work of four decades of inquiry involving Early Education educators, Shonkoff and Phillips (2000), describe early childhood work environments as being under the stress due to low wages, inevitable change, and slow progress due to turnover in the workforce. Based on more current research (Manganaro, 2003; 2009), these largely unchanged 
traits were the basis for the multiple choice question among the workplace norms and beliefs category.

Participants reported several norms including 92 percent $(n=377)$ stating that stress was a norm in their workplace; 84 percent $(n=340)$ stating that frustration with authority was a norm in their workplace; 82 percent $(n=336)$ stating that adversity to new regulations was a norm; and finally 97 percent $(n=397)$ that complaining was a norm in their workplace. When asked about congruence among co-workers' beliefs about children, families, and pedagogy, participants reported incongruent beliefs about children and pedagogy were an issue; but reported that beliefs about family (e.g., involvement, importance, and education) were consistently rated congruently among participants. Comments offered in this area were analyzed and a frequency of particular words occurred with these words: emotional, social, strict, favoritism, and positive.

\section{Educator Access to Online Resources}

Reported Types of Information and Communication Technology access included countless sites on the Internet spanning national organizations (naeyc. com), nonprofit agencies (aap.org), local government resources (ma.gov), informal blogs (mailboxmagazine. com), and corporate sponsors of resources (discountschoolsupply.com) for educators. Participants involved spanned 184 different school sites, each with differing procedures concerning teacher time away from children to use for planning purposes, including access to resources on the Internet. State regulations require that educators will not tend to any paperwork or administrative duties while supervising children. Therefore, the goal of the questions related to the access to online resources included how the participant accessed their online profile with the DOE, how often and when the online resource of the Internet was available to the educator and an open inquiry as to each participant's ideas on the use of ICT in their role as an educator.

The responses to the question about how participants accessed their online profiles with the DOE revealed that the majority, 92 percent $(n=377)$, accessed their EEC profile on paid time at their place of employment. The responses to the question about how often and when the online resource of the Internet was available to the educator revealed that 18 percent $(n=73)$ of participants had daily access to the Internet at their school, 54 percent $(n=221)$ of the participants had weekly access to Internet at their school, and 28 percent $(n=114)$ had monthly access to Internet at their school. When asked about teaching time versus non-teaching time access, the replies indicated that the Internet was not used during teaching time for teaching purposes by 91 percent $(n=373)$, that the Internet was used during teaching by 9 percent $(n=37)$. When asked about paid time versus unpaid time, the responses indicated 76 percent used the Internet 
to access work-related resources on unpaid time whereas 24 percent $(n=98)$ used the Internet to access work-related resources on paid time. When asked about how the Internet could be used to enhance information or communication in their role, respondents' data was categorized into three areas: web site school announcements, parent-teacher group communications, passwordprotected Community blogs, Facebook and social media, and human resources processes.

\section{Leadership, Online Training, and Adversity to Change}

When asked about what type of oversight participants' superiors had, the multiple choice options chosen reflected 42 percent $(n=172)$ Independent Owner, 41 percent $(n=168)$ Corporate Owner, 15 percent $(n=61)$ No Oversight (School Director is the owner), 3 percent $(n=12)$ Other. Concerning whether online resources help with program planning or behavior management, respondents reported on a Likert Scale of 1 - 5 (1 being the least helpful and 5 being the most helpful), an average rating of 4.3 to rate helpfulness in program planning and an average rating of 2.8 to rate helpfulness in behavior management. When asked how online training might help educators access information, 94 percent $(n=385)$ of participants commented and comments included names of websites that were helpful. The sites noted were categorized by site extensions. The .edu, .com, .org, and .gov comparison led to an obvious majority in comments that referred to the .org type of sites. Next in frequency were the .edu-based sites. The .com and gov sites represented a minority of comments by participants. Other comments referenced that online training was helpful to busy professionals and that human contact was also important in training. Concerning educator attitude toward workplace change, the question "To what extent do you embrace change in your workplace?" garnered replies

Table 3. Participants View of Self: Embracing Change

To what extent do you embrace change in your workplace Scale 1 - 5 (zero to very much)

\begin{tabular}{c|c|c}
\hline Answer options & Response percent & Response count \\
\hline 1 - not at all / never & $58.5 \%$ & 240 \\
\hline 2 - not often / rarely & $12.2 \%$ & 50 \\
\hline 3 - neutral / it depends & $12.2 \%$ & 50 \\
\hline 4 - sometimes / on occasion & $9.8 \%$ & 40 \\
\hline 5 - very much / frequently & $7.3 \%$ & 30 \\
\hline & Answered question & 410 \\
\hline & Skipped question & 10 \\
\hline
\end{tabular}


ranging on the Likert Scale $1-5$ used to measure extent and frequency. The replies illustrated that more than 58 percent $(n=237)$ of the educators did not look forward to or embrace change agents in the workplace (Table 3).

\section{Discussion}

\section{Educator Training and Access to Online ICT}

With regard to RQ1, RQ2, RQ3, and RQ5 and RQ6, involving participant training and the ICT access to resources in Massachusetts, there are many new opportunities through the EPS that are aligned with EEC's Licensing Regulations, Massachusetts Curriculum Frameworks, EEC's Guidelines for Preschool Learning Experiences, and Massachusetts Early Learning Guidelines for Infants and Toddlers, the Massachusetts Quality Rating and Improvement System (QRIS), and EEC's Core Competency Areas (Early Education \& Care [EEC], 2013). While all of these initiatives are quality-driven and seem to be aimed toward the common good of each child's wellbeing, the initiatives are linked to funding such that some educators are not eligible to access the resources due to a lack of connectivity to either 1) the information technology and/or 2) the resource. For instance, some funding is linked to QRIS participation/rating and/or Head Start programs. So an educator may not be eligible to access the technology and/or the resource based on where he/she works. Further, the socializing of curriculum and standards of quality may lead to a lack of individualization of a program to its immediate community. Technology initiatives therefore must match the divergent access points of not only the school site but also the educator. Attention to Winnicott (2002) on the well-being of the child may assist in the quest of quality factors, given that the changes in technology are not necessarily correlated to the needs of the small child.

\section{Workplace Access to Online ICT Systems}

Participant responses indicated that 76 percent $(n=311)$ used the Internet to access work-related resources on unpaid time whereas 24 percent $(n=98)$ used the Internet to access work-related resources on paid time. Educators require substitute coverage for their classroom to conduct any administrative type of work (including computer work) unless they are granted paid time outside of their teaching schedule in order to access online technologies. The Department of Education has assumed the role of streamlining educator information in an online information and communication technology in order to create and maintain an educator profile and to have educators self-report and document annual trainings. However, the time and resources that educators should use to conduct this work is an area of ambiguity (Sheridan \& Schuster, 2001; Shlay et al., 2005; Vaill, 1996). 
Many educators do not have access to the Internet at home. Many schools cannot afford resources to pay teachers for additional time outside the classroom (U.S. Census, 2013b). The allocation of the educator's computer time has now become the responsibility of and a cost to the employer. Because the educator must now conduct the work through the Internet, and similarly the school must ascertain that all employed educators have registered and updated their profiles online (or be out of compliance), then the school must pay for the resource and the time, and potentially, substitute-teaching time also. As indicated in the comments by participants in these surveys, the time spent on the management of online profiles potentially impedes on an educator's individual time for curriculum and behavior management planning.

\section{Workplace Norms and Attitudes about Change}

In RQ4 and RQ9 concerning workplace beliefs or norms and attitudes about change, factor analysis of latent factors resulted in various findings including the existence of norms such as 92 percent $(n=377)$ of participants reporting stress as a norm in the workplace; 84 percent $(n=344)$ reporting frustration with authority, 82 percent $(\mathrm{n}=336)$ reporting adversity to new regulations; and 95 percent $(\mathrm{n}=389)$ reporting complaining. Comments and responses in this area suggest work is stressful or intense (Green, 2004) and that further inquiry concerning shared- vision, increased informal communication using ICT such as online blogs to promote asynchronous areas where individuals can 'talk shop' and practitioners can share solutions in more open systems (Scott, 2003; Steensma \& Corley, 2001). Additionally, comments indicated that "social media might provide online options for parentteacher communications", indicating that participants seemed open to using social media in order to service parent groups. School leadership and governing agencies might consider use of social media for school communication and information sharing while ensuring the protection of the identity of children.

The analyses and results of this exploratory, mixed methods study leave practitioners with a set of new ideas for creating a blueprint toward technology integration at the local and individual school levels. The analyses also leave regulators and accreditation agencies with some areas for consideration. In the participants' selfassessment of the ability to embrace change, the possibility exists that the workforce avoids new initiatives or the idea of change and innovation due to the time constraints and negative attributes of the workplaces as reported in the surveys. Some of these norms are historically part of on this serviceindustry (Shonkoff \& Philips, 2000), but the recent initiatives by the Commonwealth of Massachusetts only add to the time restraint without devoting attention to funding or allocating Internet resources to all 
schools and educators.

Katz's ideology states that when knowledge workers do not take risks or identify change as step toward increasing quality, an organization is at a disadvantage (Katz, 2003). Given the fundamental truth of Katz's idea, the participants' report could potentially indicate a statistically significant are of consideration concerning the idea of technology and change. However, given that educators reported positive remarks about the state's online technology reporting initiative, perhaps an adaptive mindset exists, depending on the work topic and degree of proper planning and introduction of new technologies.

\section{Conclusion}

The analyses and results of this exploratory, mixed methods study leave practitioners with a set of new ideas for creating a blueprint toward technology integration at the local and individual school levels. The analyses also leave regulators and accreditation agencies with some areas for consideration.

There was a null result for Hypothesis 1; early education school educators did not have a negative perception of the Information and Communication Technology (ICT) initiatives regulated by the Massachusetts Department of Education (DOE). In fact, survey participants did not mind the systematic technology but did report a lack of resources, including computer, Internet, or paid time to use online ICT systems.
Leadership at the school level and at the regulatory level should include a plan for resource allocation so that all educators have access to the Internet.

With regard to Hypothesis 2, it shows positive results in that early education school educators perceive time taken for ICT initiatives is time that is taken away from their regular work duties (to complete the Information and Communication Technology (ICT) initiatives regulated by the Massachusetts, the Department of Education (DOE). In consideration of the time, the question of teacher responsibility versus school responsibility should include discussion about job shortages influencing the field in the current economic conditions. Perhaps in the changing world in which most professionals find themselves, educators are in a world where the only thing they can be certain of, is uncertainly itself (Handy, 1996; Zittrain, 2005). Leadership at the school level and at the regulatory level should include annual strategic planning for how educator time is spent on a weekly basis, considering in the process an educator's entire job description.

Pertaining to Hypothesis 3, there was inconclusive feedback given by early education school educators involving the Information and Communication Technology (ICT) initiatives regulated by the Massachusetts Department of Education (DOE) that time spent on these systems derails other quality initiatives. However, there is a clear need for school leadership and government agencies to dedicate 
resources and time to the ICT initiatives with consideration of the average educator's lifestyle, hours worked, and remaining cognizant of the number of hours in a work week. Otherwise, educators are taking time away from one quality area (classroom management or behavior management planning) to take on another quality area (such as self-documentation of profile and training). Leadership at the school level and at the regulatory level should include a plan for time management with considerion of educator training in proven time management programs in order to help educators manage time on task.

With regard to Hypothesis 4, results are positive in that early education school educators give favorable feedback involving the use of Information and Communication Technology (ICT) initiatives in their workplace. And, in their feedback comments, educators do point to some specific areas that individual school leadership can focus on to guide effective innovation efforts, as hypothesized. The results indicate that online parent-teacher group forums or blogs, web-site communications, and social media among adults that protect children are viewed favorably. Here again, the issue arises concerning paid time to work on ICT input and output systems. School and government leadership might consider the human side of managing technological innovations as proposed by Katz (2003) and knowledge creation as inspired by
(Kim, 2001). Leadership at the school level and at the regulatory level should include allowances for each school community to consider ICT systems for parents and educators via the Internet or otherwise.

The irreducible needs of an educator's time are difficult to discern just as the irreducible needs of children are to differentiate if one does not narrow down the most critical aspects of development (Brazelton, 2002). Time spent on the ICT inputs and outputs must be time "away from children" or "non-teaching" time because teachers cannot conduct such duties while supervising children. Yet, there is already a portion of responsibilities that educators are obligated to complete during off-teaching time. Is the educator's week a $30-, 40-$, or 50 - hour week?

Experiences recorded in the participant surveys indicate that early education school leaders should anticipate resistance and allow time to assess resources needed prior to taking on new initiatives, particularly in technology. Investing in a SMART plan (Bruno, 2011) to consider resources as well as timelines when initiating ICTrelated projects will help in the orchestration of organizational design. The organizational blueprint for school leadership should comply with the regulations and criterion set forth by state licensing and accreditation agencies. Over time, the need to balance the use of technology with other proven quality areas must be 
considered in order to best serve children and families. School and government leaders need to look into organizational models that can incorporate more compensated time for teachers to perform with ICT within their roles in order to maximize all of the quality initiatives relevant to the educator's job description. Leadership at the school level and at the regulatory level should be realistic regarding the time constraints in the planning and funding of resource allocation so that benefits are not limited to qualifying schools; rather, benefits should always be available to all licensed EEC educators involved at all licensed EEC schools. The outcomes from equal access should reach each educator, school, and child, thereby maximizing the benefit of each Commonwealth initiative.

\section{References}

Brazelton, T. (2002). The Irreducible Needs of Children. Cambridge, MA: Da Capo Press.

Bruno, H. (2009). Leading on Purpose: Emotionally Intelligent Early Childhood Administration. Boston: McGraw-Hill.

Bruno, H. (2011) What you Need to Lead: Emotional Intelligence in Practice. NAEYC.

Creswell, J. (2009). Research Design: Qualitative, Quantitative and Mixed Method Approaches. Thousand Oaks, CA: Sage Publications.

Early Education \& Care. (2013). Massachusetts
Executive Office of Education, EEC Data \& Reports. [Page: Educator and Provider Grants]. Retrieved on January 20, 2013 at http://www.eec.state.ma.us/ docs1/Workforce_Dev/20120713-fy 2013-edu-provider-crse-catalogue.pdf Gonzalez-Mena, J. \& Eyer, D. W. (2004). 8th Ed. Infants, Toddlers, and Caregivers: A Curriculum of Respectful, Responsive Care and Education. Boston: McGrawHill.

Green, F. (2004) 'Why has work effort become more intense?' Industrial Relations, 43, 709-741.

Handy, C. (1996). Beyond Certainty. Cambridge, MA: Harvard Business School Press.

Katz, R. (2003). The human side of managing technological innovation (2nd Ed.). New York: Oxford University Press.

Kim, L. (2001). Absorptive Capacity, Copetition, and Knowledge Creation. In I. Nonaka \& T. Nishiguchi (Eds.), Knowledge emergence: Social, technical, evolutionary dimensions of knowledge creation (pp. 13-29). New York: Oxford University Press.

Manganaro, M. (2003). Professionalism in child care settings: Establishing and promoting workplace norms. Child Care Information Exchange, 154(6), 72-76. Manganaro, M. (2009). Leadership In Massachusetts Early Education Schools: Perceptions of Leader Attributes In Practice. [Dissertation] Publication \#AAT 3393487; ISBN 9781109615371. Retrieved December 21, 2012 at Proquest Database.

Nishiguchi, T. (2001). Coevolution of InterOrganizational Relations. In I. Nonaka \& T. Nishiguchi (Eds.), 
Knowledge emergence: Social, technical, evolutionary dimensions of knowledge creation (pp. 13-29). New York: Oxford University Press.

Nonaka, I., Konno, N., \& Toyama, R. (2001). Emergence of "ba": A conceptual framework for the continuous and selftranscending process of knowledge creation. In I. Nonaka \& T. Nishiguchi (Eds.), Knowledge emergence: Social, technical, evolutionary dimensions of knowledge creation (pp. 13-29). New York: Oxford University Press.

Scott, W. (2003). Organizations: Rational, natural, and open systems (5th ed.). New York: Prentice Hall.

Sheridan, S., \& Schuster, K. (2001). Evaluation of pedagogical quality in early childhood education: A crossnational perspective. Journal of Research in Childhood Education. 16(1), 109-125. Retrieved December 17, 2012 from proQuest database.

Shlay, A., Tran, H., Weinraug, M., \& Harmon, M. (2005). Teasing apart the child care conundrum: A factorial survey analysis of perceptions of child care quality, fair market price and willingness to pay by low-income, African American parents. Early Childhood Research Quartely, 20(4), p393-
416. Retrieved at EBSCOhost Database on January 2, 2013.

Shonkoff, J. P., \& Phillips, D. A. (2000). From neurons to neighborhoods: The science of early education development. (p308). Washington, D.C.: National Academy Press.

Steensma, H., \& Corley, K. (2001). Organizational Context as a moderator of theories on firm boundaries for technology sourcing. Academy of Management Journal, 44(2), 271-82. Retrieved on December 2, 2012 from EBSCOhost database.

U. S. Census. (2013a). U. S. Census Bureau [Page: American FactFinder; Population Finder]. Retrieved February 28, 2013 at http:/ / factfinder.census.gov/servlet

U. S. Census. (2013b). U. S. Census Bureau [Page: Internet and Media Access]. Retrieved December 23, 2013 at http:/ / factfinder.census.gov

Vaill, P. B. (1996). Learning as a way of being: Strategies in a world of permanent white water. New York: Jossey-Bass.

Winnicott, D. W. (2002). Winnicott and the Child. Perseus Publishing: Cambridge, MA. Zittrain, J. (2005, May). In Praise of Uncertainty. Harvard Business Review, 83(5), 18-21. Retrieved December 14, 2012 from EBSCOhost database. 